\title{
Rethinking the RECAP: \\ Mapping the relational geographies of concentrated poverty and affluence in Lexington, Kentucky
}

\author{
Taylor Shelton \\ Department of Geosciences \\ Mississippi State University \\ 108 Hilbun Hall \\ Mississippi State, MS 39762 \\ email: taylor.shelton@msstate.edu
}

\section{ABSTRACT:}

The idea of concentrated poverty has long held a prominent place in understandings of racial and class inequality in American cities. While the spatial concentration of the poor is undoubtedly an important aspect of the story around urban inequality, concentrated poverty research suffers from a number of conceptual and methodological shortcomings. Through a case study of concentrated poverty and affluence in Lexington, Kentucky, this paper draws on relational socio-spatial theory and critical GIS in order to offer a constructive critique of conventional concentrated poverty research. The paper demonstrates that while concentrated poverty and affluence are both on the rise in recent years, concentrated affluence actually represents a more widespread problem within the city. At the same time, the paper visualizes how these processes are fundamentally interconnected and co-produced through property ownership relations, where the extraction of rents from areas of concentrated poverty works to simultaneously produce areas of concentrated affluence elsewhere in the city.

\section{KEYWORDS:}

concentrated poverty, critical GIS, relational socio-spatial theory, segregation, urban inequality 


\section{Introduction}

Housing is increasingly recognized as one of the primary means by which racial and class inequalities are experienced, reproduced and exacerbated in American cities. From redlining, contract sales and predatory lending to exclusionary zoning, exploitative rental markets and the gentrification of historically marginalized neighborhoods, housing inequality is seen less as a simple reflection of broader social and spatial inequalities and more a cause of them (Desmond 2012; Aalbers and Christopher 2014; Coates 2014; Burd-Sharps and Rasch 2015).

But even as housing gains traction within a broader, growing discussion of inequality in the United States, one particular way of viewing this problem remains quite dominant. This is the notion of concentrated poverty, developed originally by urban sociologist William Julius Wilson in the 1980s to explain the persistence of poverty in urban neighborhoods. The concentrated poverty idea is premised on the notion that the spatial clustering of the poor within certain neighborhoods works to exacerbate the already negative effects of poverty on individuals, families and neighborhoods across a variety of outcomes and indicators, from having increased crime rates and being at greater risk of various diseases and illnesses, to having decreased life expectancy, decreased educational performance, and a decreased likelihood of upward socio-economic mobility. In their widely-read report "Lost in Place", Cortright and Mahmoudi (2014) note that "the number of high-poverty neighborhoods in the U.S. has tripled, and the number of poor persons living in them has doubled since 1970", before continuing on to argue that " $t]$ his growing concentration of poverty is the biggest problem confronting American cities” (1).

While the spatial concentration of the poor is obviously an important aspect of the story around racial and class inequality in American cities - especially because of its ability to draw attention to housing segregation both historically and in the present day - this work can also be quite troublesome. Perhaps most important is the fact that many prominent analyses along these lines explicitly counterpose an interest in concentrated poverty with an interest in other manifestations of urban inequality, such as gentrification or income inequality, which are not separate and distinct process, but rather all outcomes of a single process of racialized capitalist urbanization. For instance, Cortright and Mahmoudi's report frames these as either/or propositions with the subtitle, "Why the persistence and spread of concentrated poverty-not gentrification-is our biggest urban challenge". This dichotomous construction was reinforced through subsequent press coverage and follow-up writing by Cortright and the likes of Richard Florida, with titles like "Stop obsessing over gentrification", "In Defense of Gentrification" and, in a slight variation, "American's Biggest Problem is Concentrated Poverty, Not Inequality" (cf. Cortright 2014, 2015; Florida 2015). Such an exclusive focus on concentrated poverty ultimately mistakes the symptom for the cause. The result of such interventions is not only policies that fail to address the underlying inequalities of racialized capitalist urbanization - even if they might be successful in ameliorating concentrations of poverty but indeed reinforce these inequalities and the social stigmas associated with communities of color that have been victims of public disinvestment for decades (Wacquant et al 2014).

This paper takes as its starting point the need to simultaneously acknowledge that concentrated poverty is indeed a substantial problem, as well as the fact that concentrated poverty can't be analytically or conceptually separated from a variety of other, related aspects of urban socio-spatial inequality. Instead, this paper draws on relational socio-spatial theory and existing critiques of the concentrated poverty concept to argue for a more processual view of concentrated poverty that explicitly links it to broader processes, most notably the problem of concentrated affluence. Such a 
perspective sees concentrated poverty not as a problem in and of itself, or separate from a host of other issues, but as one particularly spatialized symptom of broader social inequalities with respect to income and wealth inequality and the legacies of racial residential segregation in American cities.

As such, this paper analyzes both data from the US Census and property ownership records from Lexington, Kentucky in order to empirically demonstrate the growth of both concentrated poverty and concentrated affluence in Lexington, as well as the ways that racially/ethnically concentrated areas of poverty are connected to other ostensibly separate and distinct processes and places, particularly through the housing market and residential property ownership. In particular, this analysis demonstrates that the production of wealth or affluence in some parts of the city is accomplished precisely through the production of poverty in other areas, and vice versa. In adopting a critical GIS approach, this paper attempts to use official sources of quantitative data and analytical constructs to document the 'facts' of urban inequality (Wyly 2009), while also producing spatial visualizations that challenge the underlying spatial ontologies that have long dominated GIS (Sheppard 1995; O’Sullivan et al 2018; Bergmann and O’Sullivan, Forthcoming).

\section{Researching Concentrated Poverty}

Contrary to the editorializing of Cortright, Florida and others in the liberal urban policy intelligentsia, concentrated poverty isn't some long-forgotten phenomena ignored by academics and policymakers. Instead, as the following section demonstrates, there is a long and rich literature within academia and policy circles exploring concentrated poverty both empirically and conceptually. Indeed, this topic has long stimulated substantive debates and critiques around the underlying assumptions and methodologies. The following section reviews the origins and evolution of concentrated poverty research, some of the key findings from this research tradition, the major points of critique raised by geographers and other critical urban scholars, and how these critiques might be incorporated into an alternative approach to researching concentrated poverty.

\section{A. The 'Urban Underclass' and the Foundations of Concentrated Poverty Research}

While poverty has long been present in, if not fundamental to the constitution of, American society, it was only with President Lyndon Johnson's initiation of the 'War on Poverty' in the mid-1960s that poverty began to be seen as a major national concern. But following a decade or more where relatively little progress was made in ameliorating the lives of many of the most marginalized urban residents, some journalists and academics turned their attention to the persistence of this 'urban underclass' (Auletta 1982; Wilson 1987), while also seeking to go beyond the essentially cultural arguments about black poverty and pathology made popular by the likes of Daniel Patrick Moynihan (1965). In his agenda-setting work, Wilson (1987) instead pointed towards broader structural or political-economic issues - primarily in the form of deindustrialization and capital flight from inner cities, which had disproportionately adverse effects on black men's employment prospects - for the persistence and growth of urban poverty. But common across these otherwise diverging accounts was a belief that the spatial concentration of the poor in urban neighborhoods would have the impact of exacerbating the experience of poverty for those who lived there.

Continued research into concentrated poverty, largely from sociologists, has documented the evolution of these processes and further refined explanations for their existence (cf. Kasarda 1993; Massey and Fischer 2000; Squires and Kubrin 2005; Kneebone et al 2011; Lichter et al 2012). Of particular note is the growth of so-called 'neighborhood effects', which extends this tradition in 
order to understand the purported influence of one's immediate spatial context on a whole host of quality-of-life indicators (cf. Jencks and Mayer 1990; Ellen and Turner 1997; Leventhal and BrooksGunn 2000; Sampson et al 2002; Sampson 2012; Sharkey 2013). All of that is to say, concentrated poverty has been anything but ignored. Even the relative disappearance of concentrated poverty research in the early-2000s can be attributed to the fact that the economic boom of the 1990s led to significant declines in concentrated poverty (cf. Jargowsky 2003; Kingsley and Pettit 2003). And yet, even as concentrated poverty was itself on the decline, the concept continued to hold significant sway in policy circles, sitting at the center of an emerging consensus around housing and urban development policy in the US, where recommendations to disperse and deconcentrate the poor especially those living in public housing - were justified with reference to this concept and its evergrowing literature (U.S. Department of Housing and Urban Development 2013).

Despite the fact that concentrated poverty is fundamentally a geographic concept, geographers largely avoided the massive onslaught of concentrated poverty research in the 1980s and 1990s. Indeed, this is perhaps best illustrated by Leyshon's (1995) admonition of the discipline for allowing poverty to fall from its list of primary concerns. There were, of course, some notable exceptions at the time, such as special issues of Urban Geography $(1990,1991)$ on the urban underclass debates, as well as more recent work by Strait (2001), Cooke and Marchant (2006), as well as Rae (2009, 2012) on the more British variation of 'deprivation'. While geography's engagement with concentrated poverty in particular has been somewhat sporadic, geographers do have a much longer history of research into issues of poverty in the American city, such as those of Morrill (1965), Rose (1970, 1971), Harvey (1972), Blaut (1974) and Deskins (1981). But whether in reference to earlier debates about ghetto formation or more recently about the urban underclass and concentrated poverty, geographers' contributions to these discussions, however limited in comparison to other disciplines, have been to offer substantive critiques of the conceptual or methodological assumptions underpinning more mainstream research.

\section{B. Critiquing Concentrated Poverty in Theory and Practice}

While geographers have been joined by a number of other critical social scientists in their critique of the concentrated poverty concept, their contribution has been somewhat unique in being based almost entirely around the necessity of putting concentrated poverty within a broader social and spatial framework. Even before the emergence of Cortright and Florida's distinctive call to stop ignoring concentrated poverty, geographers and other urban scholars have pushed back against the tendency to simultaneously reify concentrated poverty while also ignoring the actual processes by which it has come into existence and how it might be meaningfully addressed given these origins (cf. Bauder 2002; Gans 2010; Greenbaum 2015; Dukmasova 2015). As Newman and Ashton (2004) have argued, the bracketing off of concentrated poverty from its broader context has resulted in a situation where "concentrated poverty has come to be seen in policy communities as a source of poverty itself” (1154).

Indeed, one could reasonably interpret geography's lack of whole-hearted acceptance of the urban underclass/concentrated poverty research paradigm as resulting from its consistent attempts to show how this conception of socio-spatial inequality is problematic and imbricated with a range of other social-spatial problems that were seen to be separate from supposed 'underclass' behaviors (e.g., gentrification, concentrated affluence, predatory or exclusionary finance, etc.). Beyond these broader issues with contemporary discourses on poverty, geographers and others have specifically pointed to a few key shortcomings within the literature on concentrated poverty that are worthy of 
further discussion: (1) the impoverished conception of space and spatiality; (2) the failure to understand the connections between concentrated poverty and associated phenomena, in particular the increasing concentration of affluence; and (3) the reification of quantitative indicators of concentrated poverty.

\section{Spatialities of Concentrated Poverty}

Among geographers, one of the key issues taken with concentrated poverty research lies in the way this research tends to conceptualize space and socio-spatial relations, a shortcoming that has both conceptual and methodological implications. On a methodological level, the near-exclusive use of census tract-level data has led to an impoverished conception of the neighborhood itself, which may not necessarily be appropriate for the research questions at hand (Sperling 2012; Taylor 2012). In an early geographic intervention into the urban underclass debates, Hughes (1989) argues that much of this research is based on an ecological fallacy, where all people residing in a given neighborhood are ascribed the designation of being part of the so-called underclass, based simply on their spatial proximity to people with certain characteristics. Lee et al (2008) expand on this point by point to "assumption that all persons sharing a tract, whether they are located in the core of the tract or near its edges, have no proximity to residents outside the tract but are equally proximate to everyone within its boundaries" (768).

Of course, this methodological problem with the use of relatively coarse spatial data is connected to a broader conceptual problem about how space is understood. That is, in its focus on neighborhoods and concentration as defined in very strict, binary ways, much of this research falls into the perpetual trap of treating space as if it were a static, unchanging container for social activity, rather than the product of social relations itself (Soja 1980; Lefebvre 1991). That is, areas of concentrated poverty are seen to be fundamentally separate and apart from both their immediate and broader spatial context. Gilbert (1997) summarizes this criticism succinctly, arguing that "[b]y treating the inner city as a walled off or contained space, we neglect the connections between the inner city and rest of society" (32). For Crump (2002) this means that "[t]he spatial metaphor of concentrated poverty...helps to hide the reality that the urban ghetto is the result of institutional racism which deployed government policies to purposefully segregate urban space” (586).

\section{Concentrated Poverty in Context}

The second key criticism of concentrated poverty research is that it treats the matter in isolation from other related social processes. To take the example provided by the aforementioned arguments of Joe Cortright and Richard Florida, geographic research has long provided a foundation for understanding the interrelation of concentrated poverty and gentrification through the lens of uneven development (cf. Harvey 1982; Smith 1984). That is, the necessity of capital always finding new horizons for investment means that some places be starved of such investment in the first instance. As Wilson (2007) demonstrates, the ability of different public and private actors to isolate the poor, and the social problems that purportedly follow them around, within certain predefined areas allows for the free flow of capital into those or other areas targeted for investment and redevelopment.

Even as a supposed urban renaissance of 'back to the city' movement has taken hold within some previously depressed urban neighborhoods, such a movement not only negatively affects previous residents of such a neighborhood through displacement, but also comes at the expense of other high 
poverty neighborhoods that aren't experiencing gentrification. Within the policy realm, Goetz (2015) has similarly pointed to the ways that deconcentration and dispersal strategies work to exacerbate "incipient trends toward gentrification of core areas and increasing suburbanization of poverty in American metropolitan areas" (822). As earlier sites of concentrated poverty are demolished and their residents dispersed - whether through public programs like HOPE VI and urban renewal, or through private initiative - these often centrally-located and otherwise desirable lands can then be turned over to private owners in order to reach 'the highest and best use' possible (Crump 2002).

Perhaps most powerfully, some scholars have pointed towards the need to consider the flipside of concentrated poverty - concentrated affluence - as a kind of counter-weight to the pathologizing discourse of concentrated poverty. While this notion received recent popular attention via the work of urban policy scholar Edward Goetz (cf. Semuels 2015), others have long pointed towards this potential avenue of research. As Massey (1996) argued some twenty years ago:

social scientists' attention has concentrated too narrowly on the poor and their neighborhoods. Our obsessive interest in the generation and reproduction of class is rarely focused on the affluent. Scores of ethnographers descend on the homes, bars, and street comers of the poor to chronicle their attitudes and behavior; few attempt to infiltrate the mansions, clubs, and boutiques of the wealthy to document the means by which they maintain and reproduce their affluence. The concentration of affluence and poverty means that the social lives of the rich and the poor increasingly will transpire in different venues; we must study both in order to fully comprehend the newly emerged system of stratification (Massey 1996: 409)

In response to this call, works by Massey and Eggers (1993), Coulton et al (1996), St. John (2002) and Johnson (2008) have explored the geographies of concentrated affluence in the US, while Orford (2004) has undertaken similar research in London. But as Goetz et al (2015) have demonstrated recently, many of the largest metropolitan areas in the US actually have many more racially concentrated areas of affluence than they do racially concentrated areas of poverty. So if we are in the business of identifying urban problems based solely on their size or magnitude, as Cortright and Florida suggest, then concentrated affluence certainly requires a much greater deal of attention. Indeed, even if we are simply to target such 'problems' based on their origins and on those individuals, institutions and localities that disproportionately benefit from the exclusion of the poor and non-white from certain kinds of public services (especially segregated public schools), the spatially exclusive enclaves of the affluent would be a key site of inquiry. Ultimately, however, the most appropriate path would be to understand each of these constituent processes as part and parcel of a larger trend of capitalist urban restructuring that necessitates such inequality as a precondition for continued accumulation through housing and real estate.

\section{The Failures of Concentrated Poverty Indicators}

A final major critique of concentrated poverty research leveled by critical geographers and urban social scientists regards this tradition's (largely uncritical) use of particular quantitative indicators, which often conceal as much as they reveal. Most notable here is the $40 \%$ threshold that researchers have long settled on as the point at which poverty in a census tract becomes classified as 'concentrated'. While the universality of such an approach has important benefits for allowing comparisons across time and space, this kind of standardized and inflexible indicator ultimately also works to mask the more complex, geographically contingent processes that go into producing the 
otherwise monolithic designation of 'concentrated poverty' (cf. Jargowsky 1996; Cooke 1999). Indeed, the fact that the poverty line is set by the federal government and not adjusted for local differences in the cost of living suggests that such a binary classification of poverty may be unavoidable, but nonetheless must be problematized as such. As Sessoms and Wolch (2008) argue, this kind of statistical obfuscation ultimately serves to stigmatize those places that are classified as having concentrated poverty due to a one-size-fits-all assumption about what this particular figure means for people on the ground.

Given these critiques, it's perhaps unsurprising that a variety of scholars have pushed for the use of alternative measurements of concentrated poverty, though perhaps not always with the intention of providing a more complex or nuanced understanding of the issue. On the one hand, a number of studies continue to use the tract-level percent of population in poverty as a key indicator, but adjust the threshold at which they classify an area as having concentrated poverty. For instance, Kasarda (1993) defines 'poverty tracts' as those with greater than $20 \%$ of the population under the poverty line and 'extreme poverty tracts' as those with greater than $40 \%$ under the poverty line. Lichter et al (2012) use the same 20\% threshold, but without adding an additional category, though their focus on broader geographical scales than the intra-metropolitan neighborhood perhaps makes such an adjustment more appropriate. Meanwhile, the aforementioned study by Cortright and Mahmoudi (2014) uses an alternative, lower threshold - greater than 30\% poverty - that differentiates between 'high poverty' and 'extreme poverty', as such neighborhoods would at least have double the national poverty rate.

On the other hand, some scholars have attempted a broader definition of what constitutes poverty than simply relying on the federal definition, which is derived from the cost of a minimum acceptable diet of food, albeit using a multiplier that reflects food expenditures as a percentage of income in the mid-1960s, rather than the present day. Swanstrom et al (2008) have argued that "[the $40 \%$ ] standard... has become increasingly divorced from the realities of our affluent society and ignores differences across metropolitan areas" and have instead opted to use "a relative definition of poverty based on 50 percent of median income in each region...find[ing] that the extent, geographic distribution, and trends in concentrated poverty between 1990 and 2000 are very different from those found using the federal poverty standard" (295). That is, due to the inflexibility in the definition of the federal poverty line in the first place, current indicators, whether using a $40 \%$ threshold or something lower, fail to capture the meaningful differences between places and the unequal distribution of poverty between them. Using this expanded definition based on median household income, Swanstrom et al (2008) not only show the extent of concentrated poverty to be much greater than is assumed under conventional definitions, but also that places that might otherwise not be classified as high-poverty areas are actually considerably more disadvantaged than some places that would be under conventional definitions.

\section{Thinking (and Visualizing) Concentrated Poverty Relationally}

Given these numerous critiques, an important space remains relatively unexplored regarding the potential for a reconstruction of concentrated poverty research that acknowledges its shortcomings around conceptualizations of space and spatiality, the interconnections between concentrated poverty and other processes of urban inequality, and the failure of quantitative indicators to fully represent such complexities. Put simply, concentrated poverty ought to be re-thought through a more relational lens. Such a project, to which the rest of this paper turns, represents a way of enacting the Lefebvrian call to study the production of space itself - i.e., how concentrated poverty 
actually comes to be - rather than simply the reified, a priori notion of what constitutes particular spaces and places. Following DeFilippis (2013), it is important to recognize that "[p]overty is not a function of the spatial configuration of poverty" (70), but rather is the result of broader forces in labor and housing markets, in the role of the state, and so on. By adopting such an understanding of poverty as actively produced, rather than as the more-or-less 'natural' result of particular groups of people or places, we can begin to counteract the dominant tendency for concentrated poverty measures to be used as a means of stigmatizing such marginalized places, in effect blaming the victim for their own problems (cf. Slater 2013).

Importantly, drawing on a long-established body of literature within geography around relational conceptions of space and place (cf. Massey 1991; Graham and Healey 1999; Amin 2007; Pierce et al 2011) can help to simultaneously overcome the aforementioned issues of how concentrated poverty research allows areas of concentrated poverty to be conceptually separate from both other places and processes beyond these borders. In such a relational approach, "poverty is theorized as always simultaneously produced at multiple spatial and temporal scales, rather than as territorially bounded occurrences in a discrete past or present moment" (Elwood et al 2017: 754). Or, put somewhat differently, we might argue that the processes that both produce and result from concentrated poverty are never confined to the bounded territory of the area of concentrated poverty itself. So whether we specifically look at how areas of concentrated poverty areas connected to areas of concentrated affluence within a given city, or to places beyond the city limits, such an analytical lens provides a more processual look at how both poverty and wealth are co-produced through relational processes that transcend fixed scales of analysis. Ultimately, such an approach can help to overcome what Elwood et al (2017) describe as "an obsession with measuring, benchmarking and individualizing poverty [that] has overshadowed structural analyses of its constitution and reproduction" (747), albeit without having to sacrifice the analytical and political power of mapping and quantitative data analysis.

That is, while this paper seeks to make both empirical and theoretical contributions to the study of concentrated poverty and segregation, it also attempts to extend an ever-growing body of literature on critical approaches to GIS and quantitative methods. On the one hand, this work emphasizes the potential for mapping to be used as a way of visualizing spatial inequalities in the tradition of Wyly's (2009) 'strategic positivism'. On the other hand, it also demonstrates the possibilities for visualizing alternative conceptualizations of the spatiality of injustice itself, a way of 'theorizing with GIS' (Pavlovskaya 2006). While all cartographic design is about promoting a particular way of seeing and thinking about the world and the particular subject or issue of the map at hand, a more criticallyoriented approach to the cartographic design process - or the actual doing of critical GIS - can help us to not only think about the conditions of power that shape the production of the map (cf. Crampton 2010), but also to reveal the conditions of power that shape the 'reality' being depicted in the map. Rather than simply stopping at a mapping of areas of concentrated poverty, and then reifying these places as 'problem areas' through ostensibly-objective social statistics in order to manage them (Crampton 2004), mobilizing the methods of critical GIS in conjunction with a relational understanding of space helps to produce a more complex and process-oriented understanding of how poverty is produced in conjunction with affluence, and how these processes are inherently spatial (Bergmann and O'Sullivan, Forthcoming). That is, not only can we say that poverty and affluence are co-produced, but so too can we visualize how the places that are home to concentrated poverty and affluence are also co-produced. 


\section{Mapping the Relational Geographies of Poverty and Affluence}

This section of the paper turns to an empirical analysis of concentrated poverty and affluence in Lexington, Kentucky. Lexington is a mid-sized city of just over 300,000 residents, who make up a significant majority of the roughly 480,000 inhabitants of the broader metropolitan area, who largely mirror the demographic trends within the city proper. As of $2014,72.6 \%$ of the city's population was white, $14.2 \%$ black, $6.8 \%$ Hispanic or Latino and just 3.5\% Asian or Pacific Islander. Like most cities in the American South the historic racial dynamics have focused on white and black residents, though a significant influx of Latino immigrants in the last two decades has had a meaningful impact on the city's landscape. Overall, Lexington is a reasonably affluent, growing city with a median household income of $\$ 48,667$, though $19.3 \%$ of the city's population lives below the poverty line, up from just $13.5 \%$ in 1970 , when the city had only approximately 175,000 residents. Unlike some other Southern cities, however, Lexington is unremarkable with regard to the extent of its concentrated poverty or segregation, making it an interesting case for analyzing the historical and geographical dynamics of these processes. While this analysis will document trends over time in the way racially/ethnically concentrated areas of poverty and affluence have evolved, the goal of this analysis is to analytically and visually demonstrate how, as Elwood et al (2017) argue, "poverty and privilege are mutually constituted" (747).

\section{A. Methodology and Data}

Though the starting point for this analysis are conventional Census-based measures of concentrated poverty and affluence, this study does introduce some alternative indicators that help to more fully capture the processes being studied here. As described in the previous section, the standard quantitative definition of concentrated poverty is a census tract where greater than $40 \%$ of the population lives under the poverty line. Beyond this simple indicator, a number of scholars and policy analysts have looked more specifically at 'racially concentrated areas of poverty' - or, what might perhaps more accurately be called 'racially/ethnically concentrated areas of poverty' (hereafter RECAPs) - which are concentrated poverty tracts where the population is also majority non-white. This particular measure has gained credence as part of former President Barack Obama's 2015 Affirmatively Furthering Fair Housing rule, whereby the number of RECAPs was identified as a key indicator by which these policies' success could be measured. While this paper effectively adopts this federally defined understanding of a RECAP, heeding the criticism of Swanstrom et al (2008), it's also necessary to account not just for one's binary status as above or below the poverty line, but also for their household income relative to the broader urban context. As such, the working definition of a RECAP tract for this paper is one that is majority non-white and has either greater than $40 \%$ of its population living in poverty, or which has a median household income less than $50 \%$ of the citywide median household income.

With regards to concentrated affluence, the most common measure is a household income greater than four times the poverty line, though such a measure can be fairly arbitrary (cf. St. John 2002). Instead, reversing the logic of Swanstrom et al (2008), we might say that a tract-level median household income greater than $200 \%$ of the citywide median household income signifies a considerable degree of affluence relative to a tract's immediate context (see also Coulton et al 1996, who use a figure of household income greater than $\$ 75,000$ in 1990 , which, while working within the constraints of publicly-available census data on income, represented approximately $220 \%$ of the national median household income). And while Goetz et al (2015) define racially/ethnically concentrated areas of affluence as those that are greater than $90 \%$ white, this analysis adopts a 
slightly lower, less absolute figure in order to account for the fact that the study area of Lexington is already an overwhelmingly white city. So, instead, a racially/ethnically concentrated area of affluence (hereafter RECAA) is one where a given tract has a greater percentage of white residents than the citywide average in a given year - a threshold that ranges in Lexington from 87.3\% in 1970 to just $72.6 \%$ in 2014 - while also having a median household income greater than twice the citywide median.

Table 1: Defining Racially/Ethnically Concentrated Areas of Poverty and Affluence

\begin{tabular}{|l|l|l|l|}
\hline & Race/Ethnicity & Poverty Rate & Median Household Income \\
\hline RECAP & Majority non-white & $>40 \%$ & $<50 \%$ of citywide median \\
\hline RECArP & Majority non-white & $20-40 \%$ & $50-80 \%$ of citywide median \\
\hline RECArA & More white than city as a whole & $<5 \%$ & $150-200 \%$ of citywide median \\
\hline
\end{tabular}

In addition to these adjustments, this analysis also introduces the notion of 'racially/ethnically concentrated areas of relative poverty/affluence' (hereafter RECArP and RECArA), which identifies those areas that are relatively impoverished or affluent as compared to the rest of the study area. RECArPs share with RECAPs a threshold of being majority non-white tracts, but instead have between $20-40 \%$ of the population living in poverty or a median household income between 50 $80 \%$ of the citywide median. RECArAs also share with RECAAs the race/ethnicity threshold of being more white than the city as a whole, but have median household incomes between 150-200\% of the citywide median, or, in something of a reversal of Swanstrom et al's (2008) logic, less than 5\% of the population living in poverty. Such an additional indicator would suggest areas where even if the median household income doesn't meet the threshold of conventional affluence, the almost total absence of poverty from a neighborhood signifies a particular level of exclusion working that makes such areas important for any relational analysis of urban socio-spatial inequality. The inclusion of these relative measures in this analysis, albeit disaggregated from the more absolute indicators, is meant to allow for a greater commensurability between this study and other work on concentrated poverty that uses thresholds lower than the usual $40 \%$. This schema allows all tracts that would show up in such an analysis to be captured, but also adequately differentiated such that one could identify only those tracts that meet the more stringent definitions should they wish.

Data for the initial portions of this analysis is derived from the US Census Bureau. Census data from 1970-2010 is taken from Brown University's Longitudinal Tract Database (LTDB) project, which provides estimates for census indicators harmonized to 2010 tract boundaries. 2014 data is taken from the Census' American Community Survey five-year estimates. It is important to note given the centrality of race/ethnicity to this analysis that the Census Bureau did not begin collecting information on people of Hispanic/Latino origin until 1980, though Lexington's relatively small Hispanic/Latino population until much later shouldn't substantively alter the spatial patterns evidenced in the following section.

In addition to this Census data used to track the evolution of racially/ethnically concentrated areas of poverty and affluence in Lexington, this analysis also draws on property ownership records as a way of empirically documenting the linkages between these two processes. Based on data scraped from the website of the Fayette County Property Valuation Administrator database in July 2015, this dataset includes not only the listed owner for each of the city's 109,929 parcels, but also an owner address. This additional piece of information allows us to link the location of the property with the location of the owner, visualizing the connections between places that might otherwise might be 
quite spatially distant, especially with respect to the process of wealth extraction through rent extraction.

\section{B. Trajectories of Racially/Ethnically Concentrated Poverty and Affluence in Lexington}

Using the adjusted definitions of racially/ethnically concentrated areas of (relative) poverty and affluence, Figure 1 shows the steady growth of these tracts in Lexington since 1970. While there were a total of just four such tracts displaying any degree of racially/ethnically concentrated poverty in 1970, even falling to just three such tracts in 1980, this figure has since doubled to a total of eight RECAP/RECArP tracts. Similarly, the attempt at producing a more expansive and context-sensitive definition of racially/ethnically concentrated poverty identifies more than twice as many areas as a more rigid and conventional definition, which would identify just four such tracts in 2014. Put simply, far from segregation and poverty being a thing of the past, the number of racially/ethnically concentrated areas of poverty is at an all-time high in Lexington. Indeed, if anything, this problem has actually been underestimated up to this point.

Figure 1: Growth in the Number of Racially/Ethnically Concentrated Areas of Poverty and Affluence

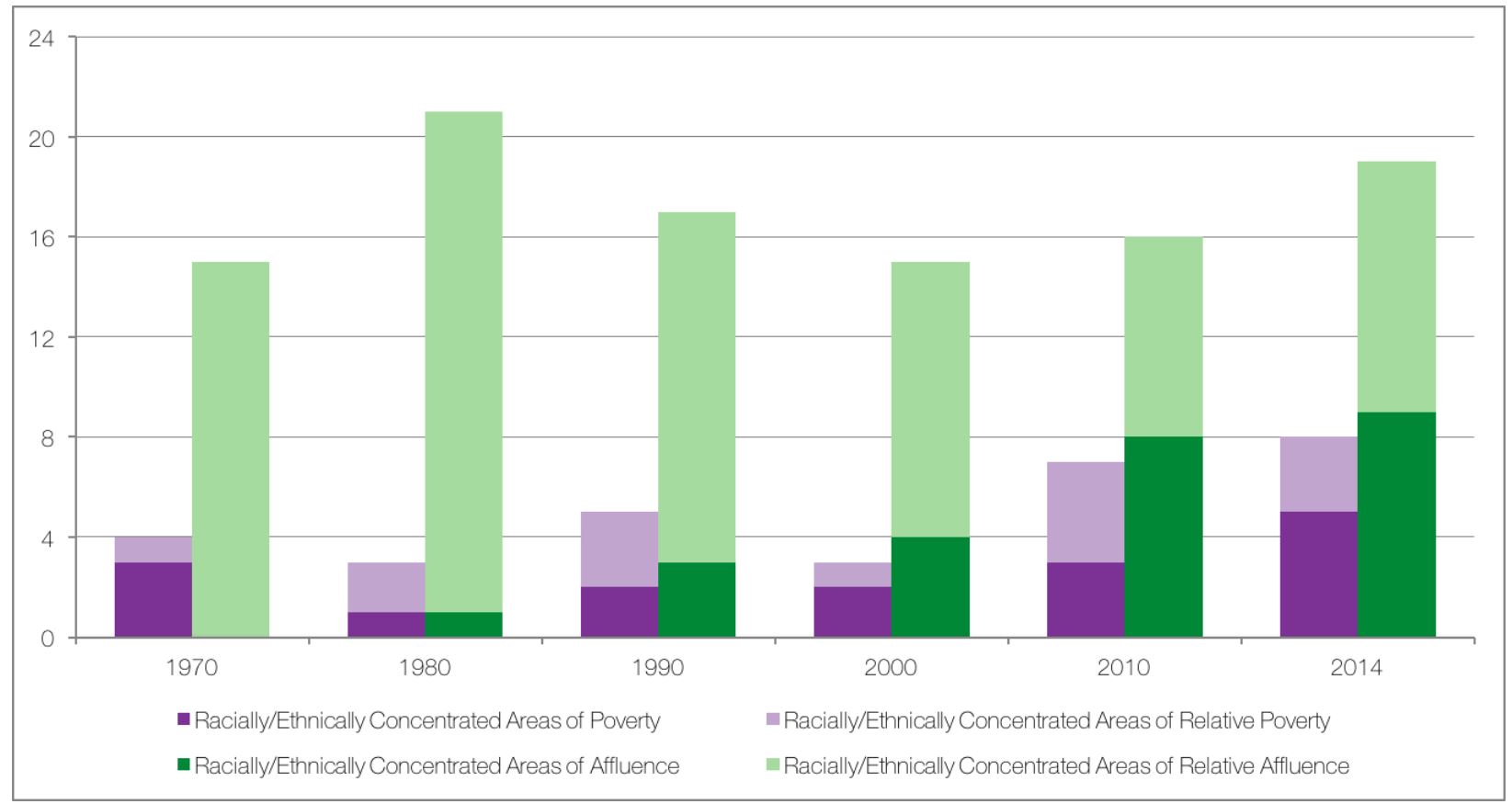

At the same time, concentrated affluence has also been on the rise. Indeed, racially/ethnically concentrated affluence is far more widespread than racially/ethnically concentrated poverty in Lexington, and has been so for quite some time. From 1970 to 2014, there are never more than eight predominantly non-white tracts classified as experiencing some degree of concentrated poverty, but never fewer than 15 tracts classified as areas of disproportionately white concentrated affluence. Even as the number of areas of relative affluence have dominated over time, especially in 1980 when there were 20 such tracts, the number of tracts classified as the more extreme racially/ethnically concentrated areas of affluence has grown the fastest of any single classification, going from being entirely absent from Lexington's landscape in 1970 to having nine such areas in 2014. While over $80 \%$ of Lexington's Census tracts were more than $90 \%$ white in 1970 , the absence of such extreme concentrations of wealth within certain neighborhoods means that tracts in this 
time are largely classified as areas of relative affluence due to the general absence of poverty, rather than high median household incomes. This suggests that even as racial segregation across Lexington has diminished over the last half-century, racial and economic outcomes have become increasingly linked, with affluent whites coalescing into and concentrating themselves within distinct enclaves within the city. Together, the growth in both racially/ethnically concentrated poverty and affluence suggests a growing bifurcation in Lexington's residential landscape.

Beyond the overall growth in racially/ethnically concentrated poverty, it is important to understand where these processes are taking place and how these areas have evolved over time. Figure 2 below visualizes the spatial distribution of tracts classified as either racially/ethnically concentrated areas of poverty or affluence from 1970 to 2014. A number of key patterns emerge from these maps. First, it is important to recognize that Lexington has long had areas of racialized poverty, and these areas are remarkably stable in their classification as such. While the more conventional definition of racially/ethnically concentrated poverty would have identified just one such area in Lexington in 1970, our definition helps to demonstrate how and where racial segregation and poverty have been intertwined historically.

While the maps in Figure 2 highlight the near-constant changes in Lexington's housing landscape with many tracts only being classified as an area of concentrated poverty or affluence for only a brief time - one can see that in spite of these changes, just three tracts remain classified as areas of racially/ethnically concentrated poverty or relative poverty in each of the six time periods analyzed here. These tracts are most visible in 1980 and 2000, at which times they represent the city's only areas of racialized concentrated poverty. Tracts 3 and 4, corresponding roughly to the city's historically black communities in the East End and Northside, are classified as areas of concentrated poverty consistently over the past half-century, with Tract 3 only being classified as an area of relative poverty in 1980. The other, tract 11, which includes the historically black neighborhood along Georgetown Street to the west, is classified as an area of relative poverty from 1970-2010 before shifting into being classified as an area of concentrated poverty in 2014. Even as these neighborhoods are largely in the same position they were in 45 years ago, these areas have also undergone significant change. In this time period, these tracts have seen anywhere from 40-80\% decreases in the total number of black residents, and declines in the proportion of black residents between $4-29 \%$. These three tracts are all also in the top 10 citywide in the percentage of total population lost from 1970-2014, ranging between a loss of 31\% of the tract population in the case of tract 11 to nearly $70 \%$ of the population in tract 4 . This demographic change accords with a more general, nationwide trend identified by Cortright and Mahmoudi (2014), where even those high poverty tracts from 1970 that stayed high poverty through 2010 lost significant amounts of population.

This trend, of course, correlates well with the long-term national urban policy priority of deconcentrating the poor. Whether through the tail end of the federal urban renewal program, the growth of the housing choice voucher program after the 1974 Housing and Community Development Act, or the widespread demolition of public housing beginning in the 1990s with the inauguration of the HOPE VI program that replaced such public housing complexes with mixedincome, mixed-use developments, the spatial dispersal of poor people has been the cornerstone of the national urban and housing policy consensus (Imbroscio 2008; Goetz and Chapple 2010). In Lexington, the overall growth of racially/ethnically concentrated areas of poverty, simultaneous with the city's own implementation of poverty deconcentration measures, suggests that such policies have done little to solve the larger problem of concentrated poverty they ostensibly seek to address, as has 
often been the case with such geographically-targeted social policies that ignore the broader forces acting upon the area in question (cf. Alcock 2005 on the history of these policies across the US and UK). While HOPE VI projects at the former sites of the Bluegrass-Aspendale and Charlotte Court housing projects (located in Census tracts 4 and 11, respectively) may have reduced crime in these areas and opened them up for new, mixed-income housing developments, the lack of a comprehensive policy approach aimed at replacing over 1,000 demolished public housing units has meant that the problem of concentrated poverty hasn't been eliminated in Lexington, it has simply moved elsewhere in the city (cf. Crump 2002; DeFilippis 2013).

Figure 2: Mapping Racially/Ethnically Concentrated Areas of Poverty and Affluence, 1970-2014
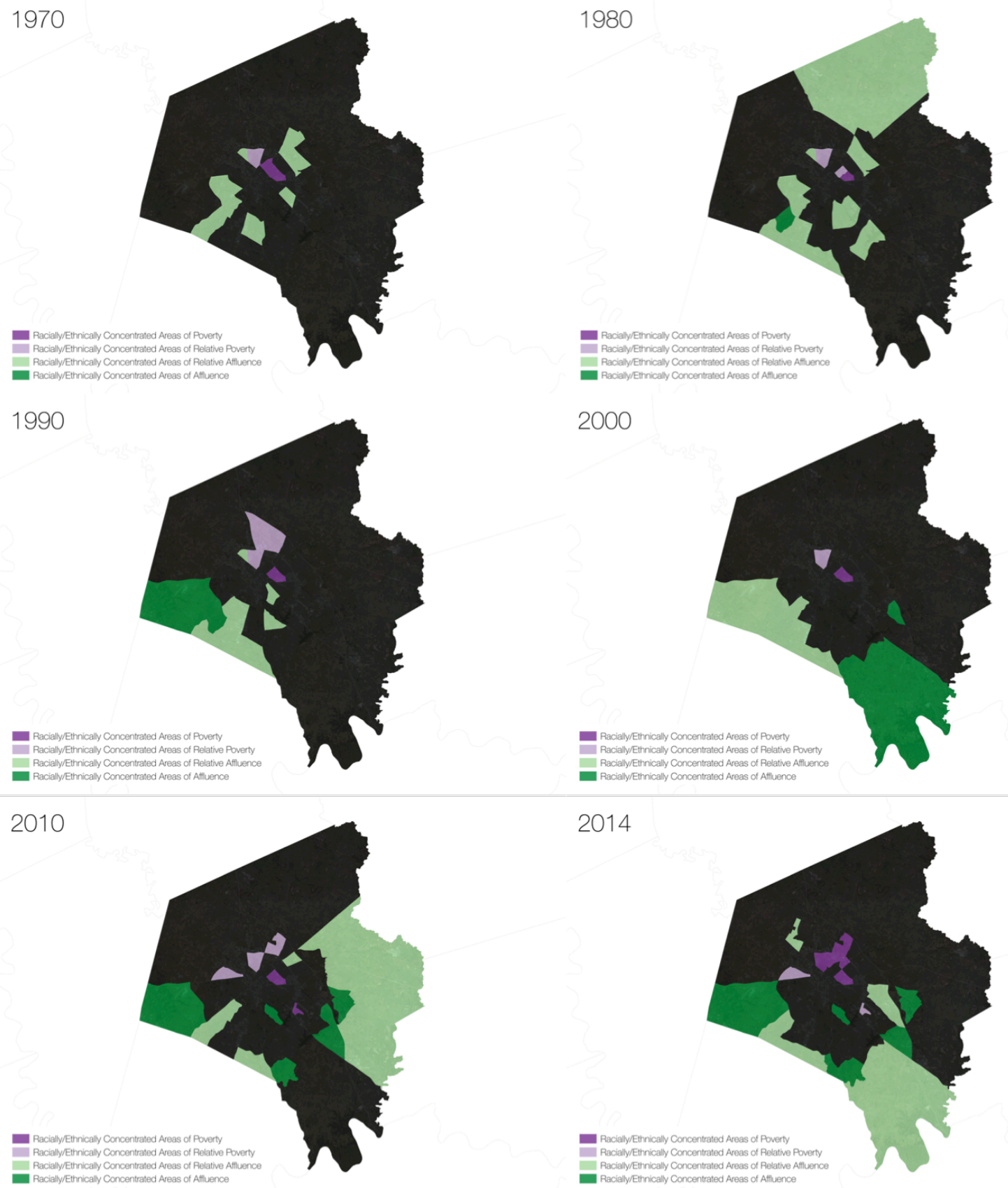
It is worth noting that throughout much of the last half-century Lexington's racially/ethnically concentrated areas of poverty have themselves been spatially concentrated within the city. Prior to the emergence of the Cardinal Valley and Woodhill neighborhoods in the city's inner eastern and western suburbs, respectively, as enclaves of non-white poverty in 2010, all of Lexington's areas of racially/ethnically concentrated poverty were located in north Lexington in either the East End, Northside, Winburn or Georgetown Street neighborhoods. On the other hand, the city's areas of concentrated affluence have seen remarkable changes in their spatial distribution since 1970. Rather than being concentrated in only a few select locations that are relatively stable over time, the concentrations of affluent whites in the city have moved around consistently, tracking very closely with the development of new suburban neighborhoods on the city's fringes in recent decades. While some more centrally-located neighborhoods like Chevy Chase, Ashland, Bell Court and Montclair have largely been bastions of affluent whites over time, the most recent data points to an even further suburbanization of white affluence in Lexington. As of 2014, nearly all of the racially/ethnically concentrated areas of affluence and relative affluence in Lexington are located outside of Man o' War Boulevard, stretching from Versailles Road in the west all the way along the city's southern border with Jessamine County around to Winchester Road in the east. While it may seem contradictory that these concentrations of wealth would be spatially dispersed across the city, this further highlights the tension with the broader understandings of space that underlie the concentrated poverty concept, which focus on concentrations only within a more-or-less arbitrarily drawn Census tract, rather than concentrations between multiple tracts. Ultimately, this pattern of concentrated affluence shifting throughout the city's suburbs suggests that as new developments are constructed at the city's fringes, they are supporting and exacerbating trends towards growing racial and class segregation.

\section{Connecting RECAPs and RECAAs}

Though it's crucial to understand bifurcation as a dominant feature of contemporary housing landscapes, the common parlance of segregation also masks the underlying processes through which this inequality is produced. That is, through concentrated poverty and affluence are in many ways opposites, they are also intimately connected and co-produced. While the descriptive analysis presented in the previous section provides an important basis for understanding both the changing nature of housing inequality in Lexington and its manifestations in particular spaces, these maps tell only a partial story. The challenge is instead to demonstrate how (even if incompletely) concentrated poverty are co-produced, part of the same fundamental process of exploitation under racialized capitalist urbanization.

Using the aforementioned dataset of property ownership records in Lexington-Fayette County, all residential properties in RECAP/RECArP tracts were identified, yielding a total of 7,127 properties. After geocoding the listed owner addresses and attempting to identify actual locations for those individuals or LLCs using post office boxes as contact addresses, a total of 7,061 residential properties with identifiable owner addresses remained. These owner addresses were then mapped and subdivided into four categories: (1) those owned within RECAP/RECArP areas, (2) those owned within RECAA/RECArA areas, (3) those owned elsewhere in Lexington, and (4) those owned outside of Lexington altogether. Of the 7,061 residential properties in our analysis, 4,168 are owned elsewhere within RECAP/RECArP tracts, while 506 (or $\sim 7.2 \%$ ) were owned in RECAA/RECArA tracts, 1,606 (or $\sim 22.7 \%$ ) are owned elsewhere in Lexington, and another 781 $(\sim 11.1 \%)$ owned outside of Lexington altogether. 


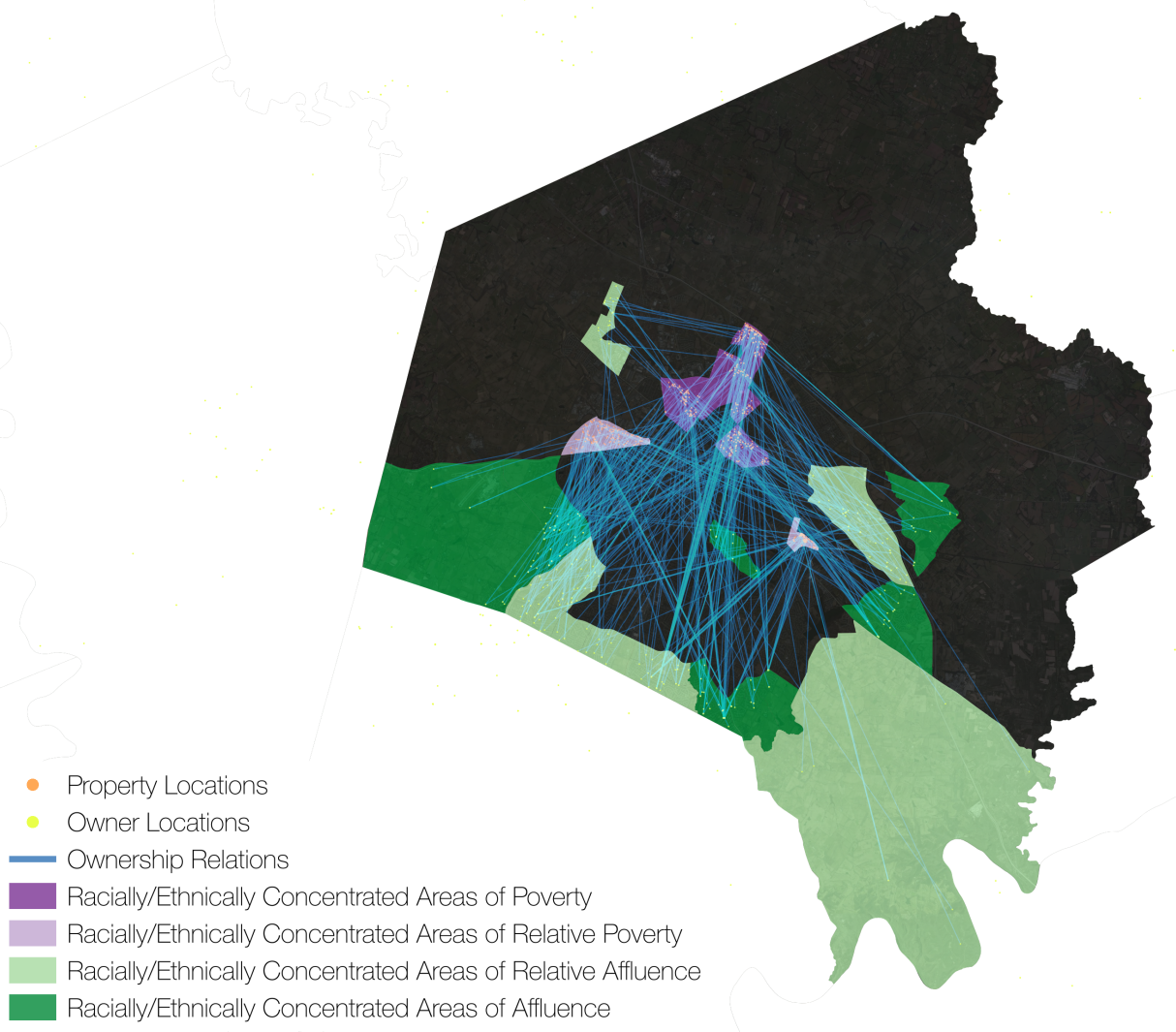

Drawing inspiration from Bunge's (1971) infamous mapping of money transfers in metropolitan Detroit, Figures 3 and 4 attempt to visualize the specific connections between areas of racially concentrated poverty and affluence through the lens of property ownership. While Figure 3 focuses exclusively on those residential properties owned in RECAA/RECArA tracts, and Figure 4 on all other locally-owned properties owned outside of either RECAP/RECArP or RECAA/RECArA tracts, cumulatively $41 \%$ of all properties in Lexington's racially concentrated areas of poverty are owned outside of these neighborhoods. Even as the ownership structure of properties in these neighborhoods represents only one of many ways in which these places are intertwined and coproduced, visualizing these relations not only highlights an alternative spatial ontology that is more relational and in tune with long-established trends within critical geography, but also an alternative understanding of how interventions into issues concentrated poverty might proceed, for example, by decentering the object of the RECAP and instead looking at the processes that go into producing the RECAP as such. Indeed, such an understanding of space challenges an ontology of 'concentration' altogether, as it suggests that even when the poor are spatially clustered, poverty is a phenomena that is spatially diffuse and networked, produced only through the interactions of poor people and neighborhoods and the wealthy people and neighborhoods that profit off of them. 


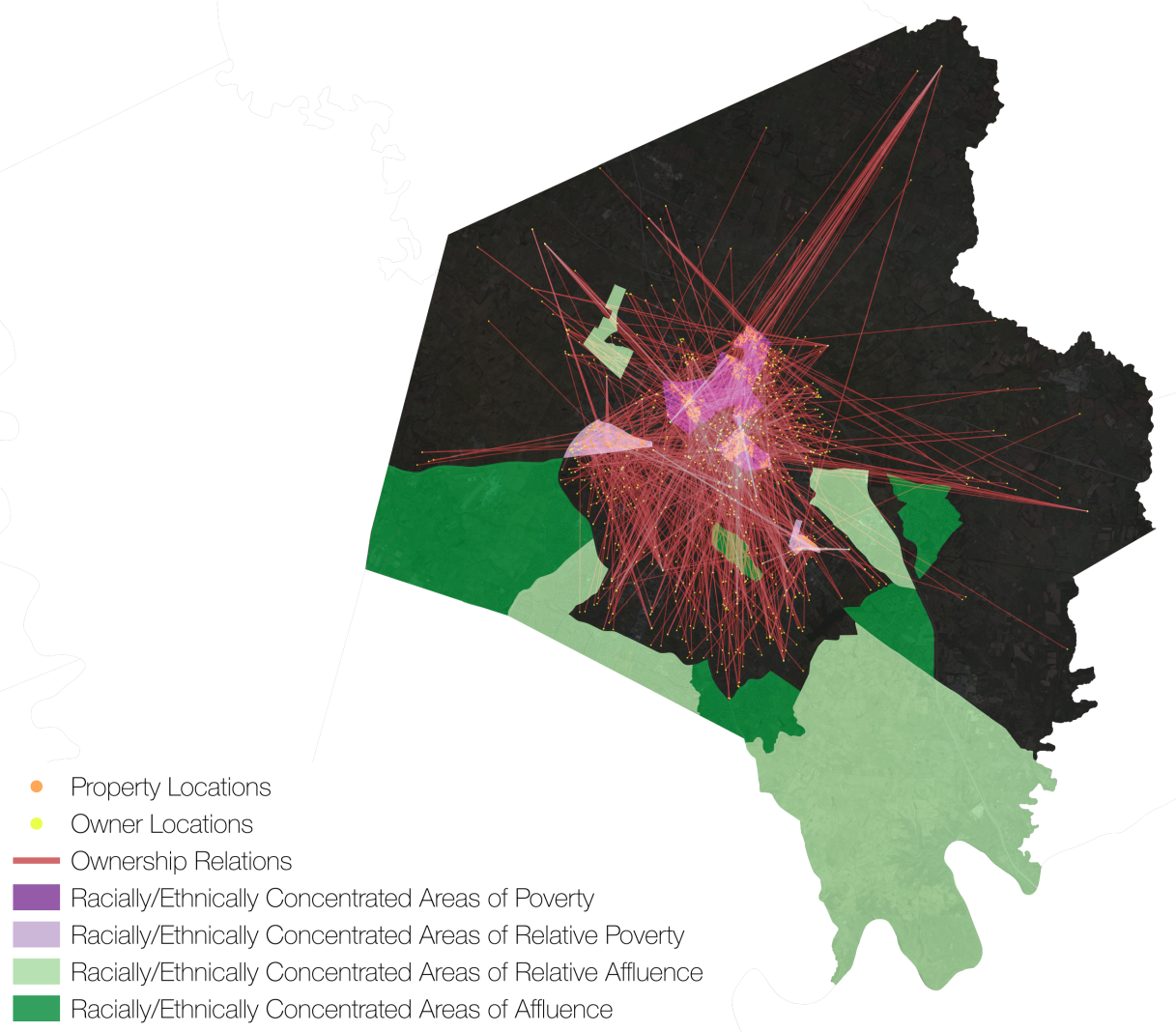

Visually, these kinds of relational mappings represent the flows and interconnections between places, emphasizing a kind of complexity that is otherwise unrepresented in more conventional mappings of concentrated poverty, such as in Figure 2. But, more analytically, the key argument these maps evoke and support is that RECAPs are far from being 'socially isolated', as conventional wisdom about concentrated poverty and racial segregation would have it. In this work, social life is simultaneously reduced to the isolated actions of individuals, while also ascribing causation for these actions to an inherent essence associated with the spatial context of impoverished neighborhoods. These maps instead demonstrate that being demographically or socio-economically distinct is something entirely different than being 'socially isolated'. Through flows of property ownership and rent extraction, these areas of racially/ethnically concentrated poverty are intimately intertwined in the social life and processes elsewhere in Lexington. The reality, however, is that this integration into social life operates almost unidirectionally and under an uneven balance of power, where the limited financial resources of neighborhoods of concentrated poverty are exploited and extracted in order to enrich, and indeed produce in the first place, white-segregated affluent neighborhoods.

\section{Conclusion}

The analysis presented in this paper, which has shown the considerable growth of both racially/ethnically concentrated poverty and affluence, suggests that Lexington is becoming an increasingly unequal and bifurcated city. In this way, this work confirms and extends the nationallevel findings of both Cortright and Mahmoudi (2014) and Goetz et al (2015) at the local level 
within Lexington. While the problems of racially/ethnically concentrated poverty have no easy, single solution, the continued growth of these areas in Lexington concurrent with policies meant to address them suggests that simply forcing the city's poor and non-white residents out of the neighborhoods they had long been segregated in hasn't ameliorated the problems these individuals and families face, only moved them further out of view. This obfuscation of growing poverty within the city has been aided by the secessionist approaches of the city's affluent whites, who have increasingly been segregating themselves in homogeneous neighborhoods at the city's suburban fringes.

At the same time, however, this analysis has attempted to transcend the simple mapping of areas of concentrated poverty and affluence by demonstrating how these places and processes are fundamentally interconnected. Rather than being seen as hermetically sealed, isolated containers of social disorganization and dysfunction, areas of racially/ethnically concentrated poverty are seen as actively produced through processes of property-based capital accumulation and uneven development that transcend their borders. That is, the very same processes of property ownership that serve to both extract wealth from predominantly black and Latino neighborhoods and limit the ability of residents in these places to control their own environment, also serve to produce the very places that are generally thought to be wholly distinct and separate from the problems of concentrated poverty, thus allowing for the simultaneous creation and growth of racially/ethnically concentrated areas of affluence.

So this effort in 'rethinking the RECAP' has attempted to not only displace the RECAP as the sole areal unit of analysis in studies of racial and class segregation in American cities and instead relocate some of that territorial stigma onto the affluent white neighborhoods that benefit from it, but also to challenge our understandings of the spatiality of poverty and inequality from one that's entirely dependent upon Census tracts and other areal units in the first place. Instead, by emphasizing a relational spatial ontology of flow and interconnection, poverty and affluence can be understood as not only confined to the arbitrary polygons of statistical geographies, but fundamentally coproduced and co-dependent in ways that transcend such static understandings of space. Indeed, as the paper argued, the ontology of spatial concentration is problematic insofar as poverty and affluence are always produced through spatially diffuse networks that link poor people and neighborhoods with their wealthier counterparts who profit off of them. Ultimately, the potential of such an approach, especially one that can continue to visualize such relational spaces in new and innovative ways, is to use mapping and data visualization as a means by which the dominant, pathological views of racialized urban poverty can be overturned and refocused on the inequalities fundamental to racialized capitalist urbanization and the sites where they are produced. 


\section{$\underline{\text { V. References }}$}

Aalbers, Manuel B., and Brett Christophers. 2014. "Centring Housing in Political Economy." Housing, Theory and Society 31 (4): 373-94.

Alcock, Pete. 2005. “"Maximum Feasible Understanding' - Lessons from Previous Wars on Poverty." Social Policy and Society 4 (3): 321-29.

Amin, Ash. 2007. "Re-thinking the Urban Social." City 11 (1): 100-114.

Auletta, Ken. 1982. The Underclass. Random House.

Bauder, Harald. 2002. "Neighbourhood Effects and Cultural Exclusion." Urban Studies 39 (1): 85-93.

Bergmann, Luke, and David O’Sullivan. Forthcoming. "Reimagining GIScience for Relational Spaces." The Canadian Geographer.

Blaut, James M. 1974. "The Ghetto as an Internal Neo-Colony." Antipode 6 (1): 37-41.

Bunge, William. 1971 [2011]. Fitrgerald: Geography of a Revolution. University of Georgia Press.

Burd-Sharps, Sarah, and Rebecca Rasch. 2015. "Impact of the US Housing Crisis on the Racial Wealth Gap Across Generations." Social Science Research Council. Available from: http://www.ssrc.org/publications/view/impact-of-the-us-housing-crisis-on-the-racialwealth-gap-across-generations/

Coates, Ta-Nehisi. 2014. "The Case for Reparations". The Atlantic. June. Available from: http://www.theatlantic.com/magazine/archive/2014/06/the-case-for-reparations/361631/

Cooke, Thomas J. 1999. "Geographic Context and Concentrated Urban Poverty Within the United States." Urban Geography 20 (6): 552-66.

Cooke, Thomas, and Sarah Marchant. 2006. "The Changing Intrametropolitan Location of HighPoverty Neighbourhoods in the US, 1990-2000.” Urban Studies 43 (11): 1971-89.

Cortright, Joe. 2014. "Stop obsessing over gentrification". New York Daily News. 10 December. Available from: http://www.nydailynews.com/opinion/joe-cortright-stop-obsessinggentrification-article-1.2040893

Cortright, Joe. 2015. "In Defense of Gentrification". The Atlantic. 31 October. Available from: http://www.theatlantic.com/business/archive/2015/10/in-defense-ofgentrification/413425/

Cortright, Joe, and Dillon Mahmoudi. 2014. "Lost in Place: Why the Persistence and Spread of Concentrated Poverty - Not Gentrification - Is Our Biggest Urban Challenge.” City Observatory. Available from: http:// cityobservatory.org/lost-in-place/

Coulton, Claudia J., Julian Chow, Edward C. Wang, and Marilyn Su. 1996. “Geographic Concentration of Affluence and Poverty in 100 Metropolitan Areas, 1990." Urban Affairs Review 32 (2): 186-216.

Crampton, Jeremy. 2004. "GIS and Geographic Governance: Reconstructing the Choropleth Map." Cartographica: The International Journal for Geographic Information and Geovisualization 39 (1): 41-53.

Crampton, Jeremy W. 2010. Mapping: A Critical Introduction to Cartography and GIS. John Wiley \& Sons. Crump, Jeff. 2002. "Deconcentration by Demolition: Public Housing, Poverty, and Urban Policy." Environment and Planning D: Society and Space 20 (5): 581-96.

DeFilippis, James. 2013. “On Spatial Solutions to Social Problems.” Cityscape 15 (2): 69-72.

Deskins, Jr., Donald R. 1981. “Morphogenesis of a Black Ghetto.” Urban Geography 2 (2): 95-114.

Desmond, Matthew. 2012. "Eviction and the Reproduction of Urban Poverty." American Journal of Sociology 118 (1): 88-133.

Dukmasova, Maya. 2015. "Our Impoverished Debate About Housing Segregation: We need to do better than breaking up 'concentrated poverty.' We need to actually understand it." Slate. 7 July. Available from: 
http://www.slate.com/articles/business/metropolis/2015/07/_concentrated_poverty_the term_has_noble_intentions_but_it_s_damaging_our.html

Ellen, Ingrid Gould, and Margery Austin Turner. 1997. "Does Neighborhood Matter? Assessing Recent Evidence." Housing Policy Debate 8 (4): 833-66.

Elwood, Sarah, Victoria Lawson, and Eric Sheppard. 2017. "Geographical Relational Poverty Studies." Progress in Human Geography 41 (6): 745-65.

Florida, Richard. 2015. "America’s Biggest Problem is Concentrated Poverty, Not Inequality". CityLab. 10 August. Available from: https://www.citylab.com/equity/2015/08/americasbiggest-problem-is-concentrated-poverty-not-inequality/400892/

Gans, Herbert J. 2010. "Concentrated Poverty: A Critical Analysis.” Challenge 53 (3): 82-96.

Gilbert, Melissa R. 1997. "Identity, Space, and Politics: A Critique of the Poverty Debates.” In Thresholds in Feminist Geography: Difference, Methodology, Representation, edited by John Paul Jones, Heidi J. Nast, and Susan M. Roberts, 29-45. Rowman \& Littlefield.

Goetz, Edward G. 2015. "From Breaking Down Barriers to Breaking Up Communities The Expanding Spatial Strategies of Fair Housing Advocacy." Urban Affairs Review 51 (6): 820-42.

Goetz, Edward G., and Karen Chapple. 2010. "You Gotta Move: Advancing the Debate on the Record of Dispersal." Housing Policy Debate 20 (2): 209-36.

Goetz, Edward, G., Tony Damiano, and Jason Hicks. 2015. "Racially Concentrated Areas of Affluence: A Preliminary Investigation". Working Paper. University of Minnesota, Humphrey School of Public Affairs.

Graham, Stephen, and Patsy Healey. 1999. "Relational Concepts of Space and Place: Issues for Planning Theory and Practice." European Planning Studies 7 (5): 623-46.

Greenbaum, Susan. 2015. "Concentrated Poverty Is the New Urban Panic." Al Jazeera America. 21 September. Available from: http://america.aljazeera.com/opinions/2015/9/concentratedpoverty-is-the-new-urban-panic.html

Harvey, David. 1972. "Revolutionary and Counter Revolutionary Theory in Geography and the Problem of Ghetto Formation." Antipode 4 (2): 1-13.

Harvey, David. 1982 [2007]. The Limits to Capital. Verso.

Hughes, Mark Alan. 1989. "Misspeaking Truth to Power: A Geographical Perspective on the 'Underclass' Fallacy.” Economic Geography 65 (3): 187-207.

Imbroscio, David. 2008. “"[U]nited and Actuated by Some Common Impulse of Passion': Challenging the Dispersal Consensus in American Housing Policy Research.” Journal of Urban Affairs 30 (2): 111-30.

Jargowsky, Paul A. 1996. "Beyond the Street Corner: The Hidden Diversity of High-Poverty Neighborhoods." Urban Geograpby 17 (7): 579-603.

Jargowsky, Paul A. 2003. "Stunning Progress, Hidden Problems: The Dramatic Decline of Concentrated Poverty in the 1990s." Living Cities Census Series. The Brookings Institution. Available from: https://www.brookings.edu/research/stunning-progress-hidden-problemsthe-dramatic-decline-of-concentrated-poverty-in-the-1990s/

Jencks, Christopher, and Susan E. Mayer. 1990. "The Social Consequences of Growing Up in a Poor Neighborhood." In Inner-City Poverty in the United States, edited by Laurence E. Lynn, Jr. and Michael G. H. McGeary. National Academies Press. pp. 111-186.

Johnson Jr., Odis. 2008. "Who Benefits from Concentrated Affluence? A Synthesis of Neighborhood Effects Considering Race, Gender and Education Outcomes.” Journal of Public Management and Social Policy 14 (2): 85-112.

Kasarda, John D. 1993. "Inner-city Concentrated Poverty and Neighborhood Distress: 1970 to 1990." Housing Policy Debate 4 (3): 253-302. 
Kingsley, G. Thomas, and Kathryn L.S. Pettit. 2003. "Concentrated Poverty: A Change in Course." Neighborhood Change in Urban America. The Urban Institute. Available from: http://www.urban.org/research/publication/concentrated-poverty-change-course

Kneebone, Elizabeth, Carey Nadeau, and Alan Berube. 2011. "The Re-Emergence of Concentrated Poverty: Metropolitan Trends in the 2000s.” Brookings Institution, Metropolitan Policy Program. Available from: https://www.brookings.edu/research/the-re-emergence-ofconcentrated-poverty-metropolitan-trends-in-the-2000s/

Lee, Barrett A., Sean F. Reardon, Glenn Firebaugh, Chad R. Farrell, Stephen A. Matthews, and David O'Sullivan. 2008. "Beyond the Census Tract: Patterns and Determinants of Racial Segregation at Multiple Geographic Scales.” American Sociological Review 73 (5): 766-91.

Lefèbvre, Henri. 1991. The Production of Space. Blackwell.

Leventhal, Tama, and Jeanne Brooks-Gunn. 2000. "The Neighborhoods They Live in: The Effects of Neighborhood Residence on Child and Adolescent Outcomes." Psychological Bulletin 126 (2): 309-37.

Leyshon, Andrew. 1995. "Missing Words: Whatever Happened to the Geography of Poverty?" Environment and Planning A 27 (7): 1021-25.

Lichter, Daniel T., Domenico Parisi, and Michael C. Taquino. 2012. "The Geography of Exclusion: Race, Segregation, and Concentrated Poverty.” Social Problems 59 (3): 364-88.

Massey, Doreen. 1991. “A Global Sense of Place.” Marxism Today 35 (6): 24-29.

Massey, Douglas S. 1996. "The Age of Extremes: Concentrated Affluence and Poverty in the Twenty-First Century." Demography 33 (4): 395-412.

Massey, Douglas S., and Mitchell L. Eggers. 1993. "The Spatial Concentration of Affluence and Poverty during the 1970s." Urban Affairs Quarterly 29 (2): 299-315.

Massey, Douglas S., and Mary J. Fischer. 2000. "How Segregation Concentrates Poverty." Ethnic and Racial Studies 23 (4): 670-91.

Morrill, Richard L. 1965. "The Negro Ghetto: Problems and Alternatives." Geographical Review 55 (3): 339-61

Moynihan, Daniel Patrick. 1965. The Negro Family: The Case for National Action. US Department of Labor, Office of Policy Planning and Research.

Newman, Kathe, and Philip Ashton. 2004. "Neoliberal Urban Policy and New Paths of Neighborhood Change in the American Inner City." Environment and Planning A 36 (7): 115172.

O'Sullivan, David, Luke Bergmann, and Jim E. Thatcher. 2018. "Spatiality, Maps, and Mathematics in Critical Human Geography: Toward a Repetition with Difference." The Professional Geographer 70 (1): 129-39.

Orford, Scott. 2004. "Identifying and Comparing Changes in the Spatial Concentrations of Urban Poverty and Affluence: A Case Study of Inner London." Computers, Environment and Urban Systems 28 (6): 701-17.

Pavlovskaya, Marianna. 2006. “Theorizing with GIS: A Tool for Critical Geographies?” Environment and Planning A 38 (11): 2003-20.

Pierce, Joseph, Deborah G. Martin, and James T. Murphy. 2011. "Relational Place-Making: The Networked Politics of Place." Transactions of the Institute of British Geographers 36 (1): 54-70.

Rae, Alasdair. 2009. "Isolated Entities or Integrated Neighbourhoods? An Alternative View of the Measurement of Deprivation." Urban Studies 46 (9): 1859-78.

Rae, Alasdair. 2012. "Spatially Concentrated Deprivation in England: An Empirical Assessment." Regional Studies 46 (9): 1183-99.

Rose, Harold M. 1970. "The Development of an Urban Subsystem: The Case of the Negro Ghetto." Annals of the Association of American Geographers 60 (1): 1-17. 
Rose, Harold M. 1971. The Black Ghetto: A Spatial Behavioral Perspective. McGraw-Hill.

Sampson, Robert J. 2012. Great American City: Chicago and the Enduring Neighborhood Effect. University of Chicago Press.

Sampson, Robert J., Jeffrey D. Morenoff, and Thomas Gannon-Rowley. 2002. "Assessing 'Neighborhood Effects': Social Processes and New Directions in Research." Annual Review of Sociology 28: 443-78.

Semuels, Alana. 2015. "Where the White People Live." The Atlantic. 10 April. Available from: http://www.theatlantic.com/business/archive/2015/04/where-the-white-peoplelive/390153/

Sessoms, Nathan J., and Jennifer R. Wolch. 2008. "Measuring Concentrated Poverty in a Global Metropolis: Lessons from Los Angeles." The Professional Geographer 60 (1): 70-86.

Sharkey, Patrick. 2013. Stuck in Place: Urban Neighborhoods and the End of Progress Toward Racial Equality. University of Chicago Press.

Sheppard, Eric. 1995. "GIS and Society: Towards a Research Agenda." Cartography and Geographic Information Systems 22 (1): 5-16.

Slater, Tom. 2013. "Your Life Chances Affect Where You Live: A Critique of the 'Cottage Industry' of Neighbourhood Effects Research.” International Journal of Urban and Regional Research 37 (2): 367-87.

Smith, Neil. 1984 [2008]. Uneven Development: Nature, Capital and the Production of Space. University of Georgia Press.

Soja, Edward W. 1980. "The Socio-Spatial Dialectic." Annals of the Association of American Geographers 70 (2): 207-25.

Sperling, Jonathan. 2012. "The Tyranny of Census Geography: Small-Area Data and Neighborhood Statistics." Cityscape 14 (2): 219-23.

Squires, Gregory D., and Charis E. Kubrin. 2005. "Privileged Places: Race, Uneven Development and the Geography of Opportunity in Urban America." Urban Studies 42 (1): 47-68.

St. John, Craig. 2002. "The Concentration of Affluence in the United States, 1990." Urban Affairs Review 37 (4): 500-520.

Strait, John B. 2001. "The Disparate Impact of Metropolitan Economic Change: The Growth of Extreme Poverty Neighborhoods, 1970-1990.” Economic Geography 77 (3): 272-305.

Swanstrom, Todd, Rob Ryan, and Katherine M. Stigers. 2008. "Measuring Concentrated Poverty: The Federal Standard vs. a Relative Standard." Housing Policy Debate 19 (2): 295-321.

Taylor, Ralph B. 2012. "Defining Neighborhoods in Space and Time." Cityscape 14 (2): 225-30.

U.S. Department of Housing and Urban Development. 2013. "Confronting Concentrated Poverty With a Mixed-Income Strategy." Evidence Matters. Available from: https://www.huduser.gov/portal/periodicals/em/spring13/highlight1.html

Urban Geography. 1990. Special Issue on "The Urban Underclass”. Urban Geography 11 (3).

Urban Geography. 1991. Special Issue on "A Continuation of the Underclass Debate". Urban Geography 12 (6).

Wacquant, Loïc, Tom Slater, and Virgílio Borges Pereira. 2014. "Territorial Stigmatization in Action." Environment and Planning A 46 (6): 1270-80.

Wilson, David. 2007. Cities and Race: America's New Black Ghetto. Routledge.

Wilson, William Julius. 1987. The Truly Disadvantaged: The Inner City, the Underclass, and Public Policy. University of Chicago Press.

Wyly, Elvin. 2009. "Strategic Positivism.” The Professional Geographer 61 (3): 310-22. 